\title{
Dietary Protein Suppresses Feedback Control of Glomerular Filtration in Rats
}

\author{
Frank D. Seney, Jr., and Fred S. Wright \\ Departments of Medicine and Physiology, Yale University, New Haven, Connecticut 06510; and Veterans Administration \\ Medical Center, West Haven, Connecticut 06516
}

\begin{abstract}
We have examined the possibility that changes in glomerular filtration rate (GFR) after changes in dietary protein intake may depend on altered function of the tubuloglomerular (TG) feedback system. We studied male Sprague-Dawley rats after dietary pretreatment for $9.6 \pm 3.6$ (SD) d with isocaloric diets containing either $6 \%$ or $40 \%$ casein. We found that GFR in rats fed the high protein diet was $24-29 \%$ higher than in rats fed the low protein diet. Simultaneous measurements of single nephron GFR (SNGFR) in the distal tubule were $6.3 \mathrm{nl} / \mathrm{min}$ or $21 \%$ higher in the rats fed the high protein diet whereas proximally measured SNGFR was not statistically different in the two groups. The higher distally measured SNGFR of rats receiving the high protein diet was associated with a $4.2 \mathrm{nl} /$ min or $\mathbf{5 0 \%}$ smaller suppression of SNGFR by TG feedback ( -4.3 vs. $-8.5 \mathrm{nl} / \mathrm{min}, P<0.001)$. Loop perfusion experiments demonstrated that in rats fed the high protein diet the TG feedback mechanism was less sensitive than in rats fed the low protein diet. The TG feedback response in rats fed the low protein diet, as assessed by reductions in stop-flow pressure and SNGFR, was half-maximal at flows of 14-15 $\mathrm{nl} / \mathrm{min}$. In contrast, the TG feedback response in rats fed the high protein diet was half-maximal at 22-24 $\mathrm{nl} / \mathrm{min}$. Maximal suppression of stop-flow pressure and SNGFR and the slope of the TG feedback response to increasing loop flow rates were not different in the two groups. We conclude that the sensing mechanism of the TG feedback system is rendered less responsive by a high protein intake, and that this change permits GFR to increase.
\end{abstract}

\section{Introduction}

Although diets rich in protein have long been known to increase whole kidney glomerular filtration rate (GFR) ${ }^{1}$ and renal blood flow $(1-10)$, relatively little is known about how

Portions of this material were presented at the 1983 annual meeting of the American Society of Nephrology in Washington, DC, and at the 1984 national meeting of the American Federation for Clinical Research in Washington, DC.

Dr. Seney is an Associate Investigator of the Veterans Administration. Dr. Wright is a Medical Investigator of the Veterans Administration.

Received for publication 18 April 1984 and in revised form 15 October 1984.

1. Abbreviations used in this paper: GFR, glomerular filtration rate; SNGFR, single nephron glomerular filtration rate; TG, tubuloglomerular.

J. Clin. Invest.

(C) The American Society for Clinical Investigation, Inc.

0021-9738/85/02/0558/11 \$1.00

Volume 75, February 1985, 558-568 these changes occur. Recently, however, two studies have provided information about the effects of protein intake on the direct determinants of glomerular filtration. Ichikawa et al. (11) found that rats maintained on a high protein diet for several months had an increased single nephron glomerular filtration rate (SNGFR). They attributed this to increases in glomerular capillary blood flow and glomerular ultrafiltration coefficient $\left(K_{\mathrm{f}}\right)$. Hostetter et al. (12) found in rats that the increases in SNGFR, glomerular capillary blood flow, and transcapillary hydrostatic pressure difference associated with substantial reductions in renal mass were largely prevented by 1-2 wk of dietary protein restriction. Thus, it may be said that protein feeding influences several determinants of glomerular filtration. Yet, the mechanisms responsible for altering these determinants remain unknown.

One mechanism capable of effecting changes in the determinants of GFR is the individual-nephron negative-feedback control pathway, the tubuloglomerular (TG) feedback system (13-17). This system serves to adjust glomerular vascular resistance (17-19) and $K_{\mathrm{f}}(17)$ in response to variations of some correlate of the early distal tubule flow rate, thereby altering the same determinants of filtration that are altered by protein feeding. The present experiments were done to examine the possibility that changes in GFR after changes in dietary protein intake may depend on altered function of the TG feedback system. The results demonstrate that a high protein intake reduces the responsiveness of the TG feedback system in otherwise normal rats. Thus, feedback suppression of GFR is reduced and GFR is allowed to rise.

\section{Methods}

Three sets of micropuncture experiments were performed, each investigating two groups of male Sprague-Dawley rats (Harlan SpragueDawley, Indianapolis, IN) fed diets (ICN Nutritional Biochemicals, Cleveland, $\mathrm{OH}$ ) containing either $6 \%$ or $40 \%$ protein (vitamin free casein). The diets, as described by others $(7,11)$, were kept isocaloric by adjusting the carbohydrate content (sucrose and corn starch). Both diets contained (in millimoles per gram of food) $0.069 \mathrm{Na}, 0.016 \mathrm{Cl}$, and $0.285 \mathrm{~K}$. The sodium and potassium contents of both diets were verified by flame photometry (model 443 , Instrumentation Laboratory, Inc., Lexington, MA) after dissolving measured amounts of food in $70 \%$ nitric acid. Equal amounts of inorganic phosphate were added to both diets. Because the casein used in the preparation of these diets contained $\sim 0.7 \%$ phosphorus (analysis by ICN Nutritional Biochemicals), the total (inorganic plus organic) phosphorus contents of the high and low protein diets were 0.28 and $0.21 \mathrm{mmol} / \mathrm{g}$. Total phosphorus contents were confirmed after dissolution of food in $70 \%$ nitric acid by the method of Amador and Urban (20). All other dietary constituents were the same in both diets. Each animal was given $20 \mathrm{~g}$ of food daily at 5 p.m.; any uneaten food was weighed and discarded just before the next feeding.

Animals were anesthetized by intraperitoneal injection of $100 \mathrm{mg} /$ kg of body wt of thiobutabarbital (Inactin, Byk Gulden, Konstanz, Federal Republic of Germany) and then maintained at $37^{\circ} \mathrm{C}$ on a heated table. Catheters were placed in the right external jugular vein 
for the infusion of saline (140 mM NaCl and $4 \mathrm{mM} \mathrm{KCl})$, the administration of [methoxy- $\left.{ }^{3} \mathrm{H}\right]$ inulin (New England Nuclear, Boston, MA) when clearance experiments were performed, and for intravenous administration of 2-4-mg supplements of anesthetic when necessary to maintain adequate anesthesia. Total infusion rate in all animals was $0.9 \mathrm{ml} / 100 \mathrm{~g}$ of body wt per $\mathrm{h}$. A catheter was placed in the left carotid artery to monitor blood pressure continuously and to collect blood samples. Mean arterial blood pressure exceeded $105 \mathrm{mmHg}$ during all measurements. The exposed left kidney was supported in a plastic cup and bathed with warmed mineral oil. All urine was collected through a cannula placed in the left ureter close to the renal pelvis.

Experiment 1. Single nephron and whole kidney GFR were measured in 14 rats, half fed the $40 \%$ protein diet and half fed the $6 \%$ protein diet. Clearance periods began no sooner than $1 \mathrm{~h}$ after starting the infusion of labelled inulin at $200 \mu \mathrm{Ci} / \mathrm{h}$. At least four blood samples $(50-60 \mu \mathrm{l})$ for determination of plasma radioactivity were obtained for each animal, usually at the beginning and end of urine collection periods. A minimum of three urine collections, each exceeding 25 min, was made for each animal. The reported GFR is the average of these values. SNGFR was measured at both distal and proximal sites in each of three to six nephrons per animal to assess SNGFR with and without flow into the loop Henle. The tip of a finding pipette (2-3 $\mu \mathrm{m}$ outside diameter, o.d.) was placed in a randomly chosen surface proximal tubule. Then small volumes of a solution containing 140 $\mathrm{mM} \mathrm{NaCl}$ and dyed with $1 \mathrm{~g} /$ liter of Hercules Mint Green $(\mathrm{H}$. Kohnstamm, New York) were injected from this pipette to determine the sequence of flow in proximal and distal segments of the selected nephron. Nephrons having two or more distal segments visible at the kidney surface were selected for study. Exactly timed tubule fluid samples were collected for 3-5 min, first from the earliest surface segment of the distal tubule and then from the last surface segment of the proximal tubule, into oil-filled collection pipettes after an oil block was placed downstream to the collection site (distal pipette, $10-11 \mu \mathrm{m}$ o.d.; proximal pipette, $12-13 \mu \mathrm{m}$ o.d.).

SNGFR was calculated as the product of the tubule fluid/plasma (TF/P) radioactivity ratio and measured tubule fluid volume per unit time. Tubule fluid volume was measured in a calibrated constant bore capillary. Tubule fluid flow rates $(\dot{V})$, reabsorption of fluid between the glomerulus and late proximal collection site $\left(J_{V}\right.$ prox $)$, and reabsorption between the late proximal and early distal sites $\left(J_{V}\right.$ loop) were calculated as described below. To determine whole kidney GFR, urine volumes were measured by weighing. Plasma radioactivity values 5 min before the midpoint of each urine collection period were interpolated from a graph on which serum radioactivity was plotted against time. Plasma counts were increased by $6 \%$ to express levels per volume of plasma water. Radioactivity of tubule fluid, urine, and plasma was determined in a liquid scintillation counter (model 6893, Searle Analytic [now TM Analytic, Elk Grove Village, IL]) using a gel suspension made with Aquasol (New England Nuclear).

In addition to presenting values for directly measured late proximal tubule flow rates $\left(\dot{V}_{\mathrm{LP}}\right)$, we present estimates of the rate of late proximal tubule flow expected had loop flow not been interrupted. This is done because loop flow and the effects of TG feedback on GFR and tubule fluid flow rate are eliminated by the technique of collecting proximal fluid used in experiment 1 . Consequently, the true rate of flow in the proximal tubule may be overestimated by this technique (21). The estimated late proximal flow rate $\left(\dot{V}_{L P}^{\prime}\right)$ is calculated as the ratio of distally measured SNGFR and the TF/P radioactivity ratio measured in the late proximal tubule: $\dot{V}_{L^{\prime}}=S_{N G F R} /(T F / P)_{L P}$. This calculation assumes that $(T F / P)_{L P}$ remains the same with or without flow through the loop of Henle. It is possible that $(\mathrm{TF} / \mathrm{P})_{L P}$ decreases to a small extent when loop flow is blocked and SNGFR increases. However, for the maximal increase in SNGFR observed in experiment 1 (see Results), we would expect (TF/P) $)_{L P}$ to decrease by not more than $10 \%$ $(22,23)$. Thus, $\dot{V}_{\mathrm{LP}}$ ' would be overestimated by not more than $11 \%$.

Reabsorption of fluid between the glomerulus and the late proximal collection site, was calculated by two methods. By using the proximal collection data, $J_{V}$ prox was calculated as $\operatorname{SNGFR}_{\mathrm{P}}-\dot{V}_{\mathrm{LP}}$. By using the distal collection data an estimated reabsorption rate in the presence of normal flow through the loop of Henle, $J_{V}$ prox', was calculated as SNGFR $_{D}-\dot{V}_{L P}$. The reabsorption of fluid between the proximal and distal collection sites was also calculated by two methods. By using the directly measured flow rates, $J_{V}$ loop was calculated as $\dot{V}_{L P}-\dot{V}_{\mathrm{ED}}$, where $\dot{V}_{\mathrm{ED}}$ is the measured flow rate in the earliest distal segment. By using the corrected late proximal flow rate, $J_{V}$ loop' was calculated as $\dot{V}_{\text {LP' }}-\dot{V}_{\text {ED }}$.

Values for $\dot{V}_{\mathrm{ED}}, \dot{V}_{\mathrm{LP}}, \dot{V}_{\mathrm{LP}}, J_{V}$ prox, $J_{V}$ loop, $J_{V}$ prox', and $J_{V}$ loop' reflect only collections that were obtained from the earliest distal and last proximal surface segments.

Experiment 2. In another group of 12 rats, half receiving each diet, the stop-flow technique was used to assess glomerular response to variations in loop flow rate. The tip of a pipette (7-8 $\mu \mathrm{m}$ o.d.), connected to a microperfusion pump (W. Klotz, Munich, Federal Republic of Germany) and containing dyed fluid resembling late proximal fluid ( $\mathrm{Na} 140 \mathrm{mM}, \mathrm{Cl} 146 \mathrm{mM}, \mathrm{K} 4.0 \mathrm{mM}, \mathrm{NaHCO}_{3} 4.0$ $\mathrm{mM}$, Ca $2.0 \mathrm{mM}, \mathrm{Mg} 1.0 \mathrm{mM}$, urea $7.0 \mathrm{mM}$, and $1.0 \mathrm{~g} /$ liter FD and $\mathrm{C}$ Blue \#1), was positioned in a random surface proximal tubule. Brief, $10-60 \mathrm{nl} / \mathrm{min}$ pulses of this fluid allowed determination of the flow pattern in the surface segments of the selected nephron. A second pipette $(2-3 \mu \mathrm{m}$ o.d.) containing $1.0 \mathrm{M} \mathrm{NaCl}$ and $1.0 \mathrm{~g} /$ liter dye (Hercules Mint Green) and connected to a servo-nulling pressure transducer (W-P Instruments, New Haven, CT) was positioned in the first surface proximal segment to record (Brush 440, Gould Inc., Cleveland, $\mathrm{OH}$ ) intraluminal pressure. The first pipette was then repositioned in the last proximal segment and was used thereafter to pump fluid into the loop of Henle. The pump rate was initially set at $2 \mathrm{nl} / \mathrm{min}$. The first puncture site was sealed with paraffin wax (E. Merck, Darmstadt, Federal Republic of Germany) delivered from a third pipette connected to a hydraulic microdrive apparatus (Trent Wells, South Gate, CA). When the wax block was three or more segments upstream to the last proximal segment, a second wax block was placed just upstream to the segment containing the pump pipette. Proximal tubule pressure then rose to a stable stop-flow pressure $\left(P_{\mathrm{SF}}\right)$. Then, while stop-flow pressure was recorded continuously, the pump setting was increased to $10,20,30$, or $40 \mathrm{nl} / \mathrm{min}$. The pump setting was returned to $2 \mathrm{nl} / \mathrm{min}$ for at least $1 \mathrm{~min}$ between each new pump setting. At least one $5-\mathrm{nl} / \mathrm{min}$ increment from the pump setting first eliciting a decrease in stop-flow pressure was also studied. In this fashion each nephron was studied at a minimum of five pump settings in addition to the baseline setting $(2 \mathrm{nl} / \mathrm{min})$. This procedure was followed in two to five nephrons per animal.

Müller-Suur et al. (24) drew sigmoid curves to summarize measurements of maximum feedback response and the loop flow rate at which TG feedback is half-maximal. Briggs (25) extended this approach by employing a sigmoid curve equation. Fitting the sigmoid curve to experimental data permits estimation of the slope at the steepest portion of the feedback response curve, as well as the maximum response and the half-maximal flow rate. Selén et al. (26) also used a sigmoid curve equation. The curve-fitting procedure that we employed has not been described previously. Our method, which is outlined in the Appendix, employed linear transformation of a sigmoid curve equation and applied least squares regression analysis to the transformed data.

Experiment 3. In a third micropuncture experiment 10 animals, half receiving each diet, were used to determine the response of SNGFR to variations in loop flow rate. $\left[{ }^{3} \mathrm{H}\right]$ inulin was infused as in experiment 1 . Nephrons were prepared for study in a fashion similar to that used in experiment 2 . In this case the pressure-recording pipette was used to measure free-flow pressures and was then used to monitor tubule pressure while fluid was collected. A wax block was placed in a midproximal segment. A vent was created just upstream to the wax block so that filtration could proceed freely between collections. Four to six samples of tubule fluid were collected (3-5 min each) from the segment proximal to the wax block while loop flow rate was varied in randomly ordered increments over the $2-40 \mathrm{nl} / \mathrm{min}$ range. Single nephron and whole kidney GFR were determined as above. The rate 
of pump delivery was verified for each perfusion pipette by pumping perfusate containing small known amounts of [carboxyl- $\left.{ }^{14} \mathrm{C}\right]$ inulin (New England Nuclear) directly into scintillation vials.

We found in the first two experiments that rats fed the high protein diet grew faster and had larger kidneys than the rats fed the low protein diet (see Results). To evaluate the possibility that any differences observed in these experiments might depend on differences in kidney size, we selected animals for experiment 3 so that the kidneys of the low protein group would be at least as large as the kidneys of the high protein group. To achieve this we placed low protein animals on dietary pretreatment when they weighed $\sim 270 \mathrm{~g}$. The high protein animals were begun on their diet when they weighed $\sim 220 \mathrm{~g}$.

Statistics. Results from the high and low protein groups were compared by the unpaired $t$ test (27). For whole rat or whole kidney results $n$ was the number of rats compared. For micropuncture results $n$ was the number of nephrons compared. Where indicated, pooled data from the high and low protein groups were compared by Scheffe's $F$ test (28). The terms "not different" and "not significantly different" indicate that no statistically significant difference was found $(P \geq 0.05)$. Calculation of the least significant difference (27) was performed where indicated.

\section{Results}

Systemic factors. Animals in the high and low protein groups ate similar amounts of chow for similar periods of time (Table I). In spite of this, animals fed the $40 \%$ (high) protein diet grew faster than animals fed the $6 \%$ (low) protein diet $(7.1$ vs. $2.7 \mathrm{~g} /$ day, $P<0.001$ ). As a result, the animals fed the high protein diet in experiments 1 and 2 weighed $10 \%$ and $17 \%$ more at the time of study (body weight, final) even though the body weights prior to dietary pretreatment (body weight, initial) were not different in the two diet groups. The relatively larger body weights of animals fed the low protein diet in experiment 3 reflect an effort to ensure that the kidneys of these animals were at least as large as the kidneys of animals receiving the high protein diet. Mean arterial blood pressure (MAP) recorded immediately after placement of the arterial catheter in the anesthetized animals, MAP (initial), was significantly higher in the low protein groups of experiments 1 and 2. The average initial MAP value for all animals fed the low protein diet, $155.0 \mathrm{mmHg}$, was also significantly higher than the comparable value for the animals fed the high protein diet, $143.3 \mathrm{mmHg}(P<0.05$ by Scheffe's $F$ test). During the sub- sequent study periods neither the blood pressures, MAP (during), nor the hematocrits differed between the two dietary groups.

Whole kidney results. In experiment 2, kidney weight, shown in Table II, was significantly less in the rats receiving the low protein diet $(P=0.007)$. In experiments 1 and 3 , kidney weights were not statistically different in the two diet groups. Urine flow rates were not different, comparing the low and high protein groups within experiments 1 and 3. However, the rate of sodium excretion, measured in experiment 3 , was twice as great in the rats receiving the low protein diet $(P$ $=0.044$ ).

GFR, measured in experiment 1 , was $29 \%$ higher $(P$ $<0.001$ ) in the animals fed the high protein diet (Table II). In experiment 3 , where the kidney weights of the two diet groups were $1.54 \pm 0.04$ and $1.54 \pm 0.05 \mathrm{~g}$, GFR values were $24 \%$ higher $(P=0.003)$ in the high protein group.

Micropuncture results. Similar filtration rate differences between diet groups were evident in the values for SNGFR determined by collecting fluid from the distal tubule. As shown in Table III, the distally measured SNGFR values were $6.3 \mathrm{nl}$ / min or $21 \%$ higher in the high protein group $(P<0.001)$. In contrast, the proximally measured values were not found to be statistically different. The proximal - distal $(P-D)$ difference in SNGFR was $4.2 \mathrm{nl} / \mathrm{min}$ or $50 \%$ less in the animals fed the high protein diet $(P<0.001)$.

The tubule flow rates measured in experiment 1 are also shown in Table III. Flow rates measured at the earliest distal site $\left(\dot{V}_{\mathrm{ED}}\right)$, were found to be slightly higher in high protein animals. Flow rates measured at the late proximal site $\left(\dot{V}_{\mathrm{LP}}\right)$ were not statistically different in the two groups. As described above, a corrected value for the late proximal flow rate $\left(\dot{V}_{\mathbf{L P}}{ }^{\prime}\right)$ may be a truer estimate of the flow rate when flow into the loop of Henle is not blocked. Like the uncorrected values, the $\dot{V}_{\text {LP' }}$ values in the high and low protein groups were not significantly different. Reabsorption of tubule fluid between the glomerulus and the late proximal site estimated from the proximal collection data ("proximal" reabsorption, $J_{V}$ prox) was $3.1 \mathrm{nl} / \mathrm{min}$ or $20 \%$ greater in the high protein group ( $P$ $=0.014)$. Using the corrected values for late proximal flow rate and the distally measured SNGFR, the higher rate of proximal reabsorption in the high protein diet group is more

Table I. Systemic Factors

\begin{tabular}{|c|c|c|c|c|c|c|}
\hline \multirow[b]{2}{*}{$\begin{array}{l}\text { Diet: } \\
n:\end{array}$} & \multicolumn{2}{|c|}{ Experiment 1} & \multicolumn{2}{|c|}{ Experiment 2} & \multicolumn{2}{|c|}{ Experiment 3} \\
\hline & $\begin{array}{l}6 \% \\
7\end{array}$ & $\begin{array}{l}40 \% \\
7\end{array}$ & $\begin{array}{l}6 \% \\
6\end{array}$ & $\begin{array}{l}40 \% \\
6\end{array}$ & $\begin{array}{l}6 \% \\
5\end{array}$ & $\begin{array}{l}40 \% \\
5\end{array}$ \\
\hline Daily food intake, $g$ & $18.9 \pm 0.2$ & $18.1 \pm 0.3$ & $19.7 \pm 0.2$ & $19.6 \pm 0.2$ & $20.0 \pm 0$ & $18.9^{*} \pm 0.4$ \\
\hline Days on diet & $12.1 \pm 1.6$ & $8.6 \pm 1.5$ & $10.0 \pm 1.7$ & $10.5 \pm 1.2$ & $8.2 \pm 1.0$ & $7.6 \pm 1.0$ \\
\hline BW (initial), $g$ & $217 \pm 4$ & $213 \pm 3$ & $222 \pm 4$ & $217 \pm 5$ & $267 \pm 6$ & $218^{*} \pm 3$ \\
\hline BW (final), $g$ & $248 \pm 5$ & $274^{*} \pm 11$ & $252 \pm 5$ & $294^{*} \pm 8$ & $291 \pm 5$ & $268^{*} \pm 5$ \\
\hline MAP (initial), $\mathrm{mmHg}$ & $152 \pm 3$ & $138^{*} \pm 3$ & $159 \pm 3$ & $142 * \pm 3$ & $154 \pm 6$ & $153 \pm 5$ \\
\hline MAP (during), $m m H g$ & $131 \pm 5$ & $122 \pm 4$ & $132 \pm 3$ & $125 \pm 2$ & $131 \pm 8$ & $124 \pm 5$ \\
\hline Hematocrit & $47.8 \pm 0.7$ & $48.5 \pm 0.5$ & & & $50.7 \pm 0.7$ & $48.9 \pm 0.4$ \\
\hline
\end{tabular}

Values are means \pm 1 SEM. $n=$ number of rats. BW (initial), body weight before dietary pretreatment; BW (final), body weight just before anesthesia; MAP (initial), mean arterial pressure immediately after placement of arterial catheter; MAP (during), average MAP during periods with kidney exposed. * Significant difference $(P<0.05)$ from the mean of the other diet group in the same experiment. 
Table II. Kidney Measurements

\begin{tabular}{|c|c|c|c|c|c|c|}
\hline \multirow[b]{2}{*}{$\begin{array}{l}\text { Diet: } \\
n:\end{array}$} & \multicolumn{2}{|l|}{ Experiment 1} & \multicolumn{2}{|l|}{ Experiment 2} & \multicolumn{2}{|l|}{ Experiment 3} \\
\hline & $\begin{array}{l}6 \% \\
7\end{array}$ & $\begin{array}{l}40 \% \\
7\end{array}$ & $\begin{array}{l}6 \% \\
6\end{array}$ & $\begin{array}{l}40 \% \\
6\end{array}$ & $\begin{array}{l}6 \% \\
5\end{array}$ & $\begin{array}{l}40 \% \\
5\end{array}$ \\
\hline $\mathrm{KW}, g$ & $1.40^{*} \pm 0.04$ & $1.54^{*} \pm 0.05$ & $1.25 \pm 0.07$ & $1.73 \ddagger \pm 0.13$ & $1.54 \pm 0.04$ & $1.54 \pm 0.05$ \\
\hline$\dot{V}_{\mathrm{U}}, \mu l / \min$ & $1.75 \pm 0.14$ & $1.92 \pm 0.15$ & & & $2.75 \pm 0.36$ & $2.60 \pm 0.21$ \\
\hline$E_{\mathrm{Na}}, n e q / \min$ & & & & & $306 \pm 65$ & $141 \ddagger \pm 21$ \\
\hline GFR, $\mathrm{ml} / \mathrm{min}$ & $0.95 \pm 0.03$ & $1.23 \dagger \pm 0.04$ & & & $1.09 \pm 0.04$ & $1.35 \ddagger \pm 0.04$ \\
\hline
\end{tabular}

Values are means \pm 1 SEM. $n=$ number of rats (except where ${ }^{*}$ indicates measurements in three rats). KW, kidney weight; $\dot{V}_{\mathrm{U}}$, urine flow rate; $E_{\mathrm{Na}}$, sodium excretion rate; GFR, inulin clearance, all for left kidney. $¥$ Significant difference $(P<0.05)$ from the mean of the other diet group in the same experiment.

evident. $J_{V}$ prox' was $4.6 \mathrm{nl} / \mathrm{min}$ or $37 \%$ higher in the high protein group $(P<0.001)$. Reabsorption of fluid between the late proximal and early distal sites estimated from uncorrected flow rates ("loop" reabsorption, $J_{V}$ loop) was $3.4 \mathrm{nl} / \mathrm{min}$ or $20 \%$ lower in the high protein group $(P=0.013)$. $J_{V}$ loop' was not statistically different in the two groups.

Experiments 2 and 3 employed loop-perfusion techniques to study the activity of the TG feedback system. In both experiments it was possible to fit sigmoid curves to the data from single nephrons. Examples are given in Figs. 1 and 2. The curve-fitting procedure, outlined in the Appendix, yields the value for the loop-perfusion rate at which the TG feedback response is half-maximal $\left(\dot{V}_{1 / 2}\right)$, and an estimate of the slope of the feedback response at this flow rate $\left(\mathrm{f}^{\prime}\left(\dot{V}_{1 / 2}\right)\right)$. Fig. 3 shows curves representing all nephrons of experiment 2 . The parameters of these curves were determined by averaging the parameters obtained for individual nephrons (Table IV). Stopflow pressure $\left(P_{\mathrm{SF}}\right)$ decreased from maximum values at loopperfusion rates $<5 \mathrm{nl} / \mathrm{min}$ to minimum values at pump rates $>30 \mathrm{nl} / \mathrm{min}$. In the low protein diet group, maximum and

Table III. Single Nephrons, Free-flow

\begin{tabular}{|c|c|c|c|}
\hline & $6 \%$ & $40 \%$ & $P$ \\
\hline & $n l / m i n$ & $n l / m i n$ & \\
\hline $\operatorname{SNGFR}_{D}(30 / 31)$ & $30.2 \pm 0.7$ & $36.5 \pm 0.9$ & $<0.001$ \\
\hline $\operatorname{SNGFR}_{P}(30 / 31)$ & $38.8 \pm 1.1$ & $40.8 \pm 1.1$ & 0.18 \\
\hline$P-D(30 / 31)$ & $8.5 \pm 0.8$ & $4.3 \pm 0.6$ & $<0.001$ \\
\hline$\dot{V}_{\mathrm{ED}}(26 / 25)$ & $6.8 \pm 0.4$ & $9.2 \pm 0.9$ & 0.023 \\
\hline$\dot{V}_{\mathrm{LP}}(20 / 26)$ & $23.1 \pm 1.3$ & $21.0 \pm 1.1$ & 0.21 \\
\hline$\dot{V}_{\mathrm{LP}}(20 / 26)$ & $17.8 \pm 0.6$ & $18.8 \pm 0.9$ & 0.39 \\
\hline$J_{v} \cdot \operatorname{prox}(20 / 26)$ & $15.5 \pm 0.9$ & $18.6 \pm 0.8$ & 0.014 \\
\hline$J_{V} \cdot$ prox $^{\prime}(20 / 26)$ & $12.3 \pm 0.8$ & $16.9 \pm 0.8$ & $<0.001$ \\
\hline$J_{V}$ loop $(18 / 21)$ & $17.1 \pm 1.0$ & $13.7 \pm 0.8$ & 0.013 \\
\hline$J_{V}$ loop' $^{\prime}(18 / 21)$ & $11.8 \pm 0.4$ & $10.9 \pm 0.5$ & 0.18 \\
\hline
\end{tabular}

Values are means \pm 1 SEM for experiment 1 . Numbers in parentheses indicate nephrons studied in the two diet groups, $6 \% / 40 \%$. SNGFR and SNGFR $_{P}$, distally and proximally measured SNGFR; $P-D$ is $\mathrm{SNGFR}_{\mathrm{P}}-\mathrm{SNGFR}_{\mathrm{D}} ; \dot{V}_{\mathrm{ED}}$ and $\dot{V}_{\mathrm{LP}}$, tubule fluid flow rates measured in early distal and late proximal tubule; $\dot{V}_{\mathrm{LP}}$, corrected rate of flow in early distal tubule (see Methods); $J_{1}$.prox, $J_{V}$. prox', $J_{1} \cdot$ loop, and

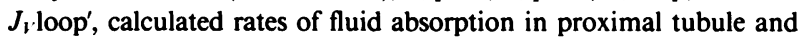
loop of Henle. minimum values for $P_{\mathrm{SF}}$ were $42.2 \pm 1.0$ and $34.1 \pm 1.2 \mathrm{mmHg}$. In the high protein diet group, maximum and minimum values for $P_{\mathrm{SF}}$ were $45.9 \pm 1.4$ and $37.9 \pm 1.8 \mathrm{mmHg}$. The maximal suppression of $P_{\mathrm{SF}}(\mathrm{H}-\mathrm{L}$ in Table IV) was not different in the high and low protein groups. Neither were the slopes calculated at the $\dot{V}_{1 / 2}$ different. However, the ranges of perfusion rates eliciting reduction of stop-flow pressure were strikingly different. In low protein animals, $P_{\mathrm{SF}}$ decreased by at least $2 \mathrm{mmHg}$ at loop-perfusion rates of 10 or $15 \mathrm{nl} / \mathrm{min}$ (19 of 20 nephrons) and approached maximal values at a perfusion rate of $\sim 20 \mathrm{nl} / \mathrm{min}$. In contrast, $P_{\mathrm{SF}}$ reductions of at least $2 \mathrm{mmHg}$ in high protein animals did not begin until $\dot{V}_{\mathrm{LP}}$ reached or exceeded $20 \mathrm{nl} / \mathrm{min}$ (18 of 18 nephrons) and approached maximal values at a perfusion rate of $\sim 30 \mathrm{nl} /$ min. As a result, the $\dot{V}_{1 / 2}$ in low protein animals was significantly lower, 14.6 vs. $23.6 \mathrm{nl} / \mathrm{min}(P<0.001)$.

In experiment 3 , SNGFR also decreased from maximal values at loop-perfusion rates $<5 \mathrm{nl} / \mathrm{min}$ to minimum values at pump rates $>30 \mathrm{nl} / \mathrm{min}$. The maximum and minimum values for SNGFR in the low protein diet group were $56.3 \pm 4.3$ and $33.7 \pm 2.9 \mathrm{nl} / \mathrm{min}$. These values were not different from the maximum and minimum values for SNGFR in the high protein diet group, $54.5 \pm 5.0$ and $33.8 \pm 3.6 \mathrm{nl} / \mathrm{min}$. As shown in Fig. 4 and Table $\mathrm{V}$, the relation in both diet groups between SNGFR and loop-perfusion rate was very similar to the relation between $P_{\mathrm{SF}}$ and loop-perfusion rate (Fig. 3, Table IV). The maximal suppression of SNGFR was not different in the dietary groups. Neither were the slopes calculated at $\dot{V}_{1 / 2}$ statistically different. As was the case for the $P_{\mathrm{SF}}$ responses, however, the ranges of perfusion rates eliciting reductions of SNGFR were significantly different. The $\dot{V}_{1 / 2}$ was significantly lower in low protein animals, $14.9 \mathrm{vs.} 22.9 \mathrm{nl} / \mathrm{min}(P=0.025)$. Thus, we found that the effects of changes of loop-perfusion rate on glomerular filtration rate, determined by direct single nephron clearance measurements, were in close agreement with the effects on glomerular capillary pressure, indicated by changes in stop-flow pressure.

\section{Discussion}

It is now recognized that one of the mechanisms serving to control the rate of glomerular filtration operates at the single nephron level and responds to changes in some correlate of the flow rate in the early distal nephron (13-17). In a general sense, the magnitude of a change in SNGFR, in relation to the magnitude of a change in loop of Henle flow rate, is an 


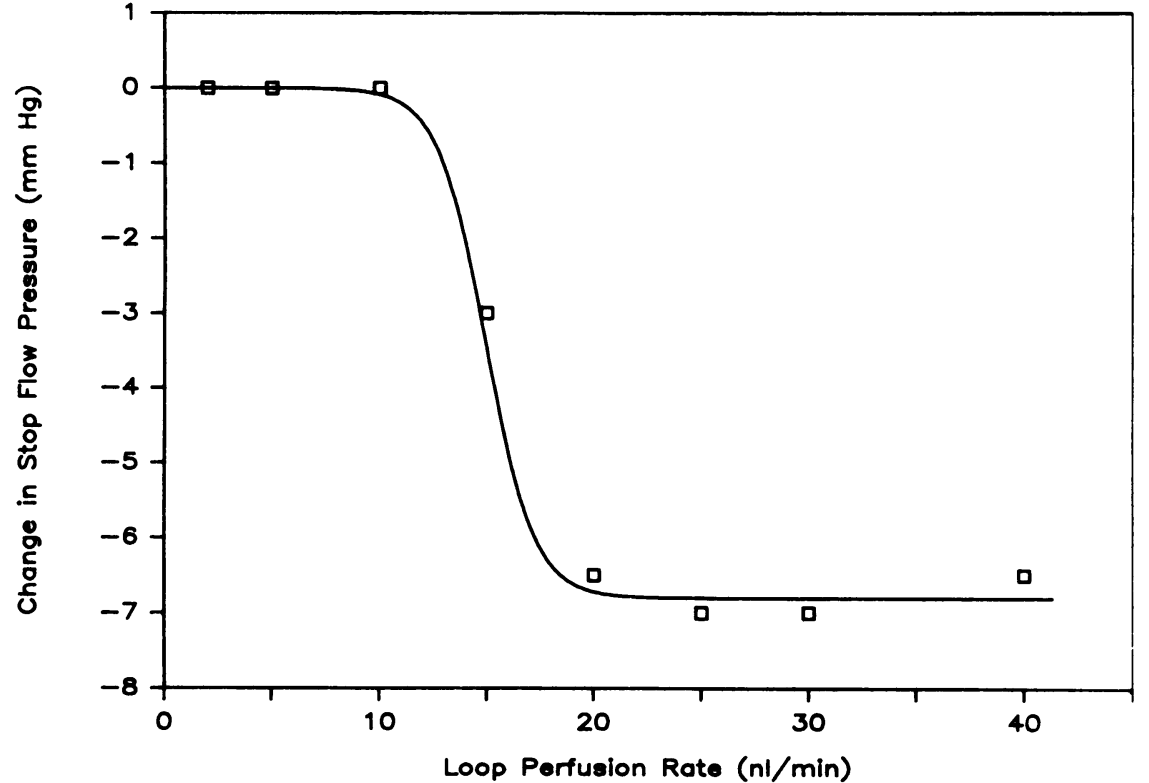

Figure 1. Example of curve fitting. Data are from one nephron in a rat fed the $6 \%$ casein diet (rat 23, experiment 2). Symbols ( $\square$ ) represent changes in stop-flow pressure $\left(P_{\mathrm{SF}}\right)$ observed at each loop-perfusion rate relative to $P_{\mathrm{SF}}$ when perfusion rate was $2 \mathrm{nl} / \mathrm{min}$. The line is the sigmoid curve (Eq. 3 in Appendix) fit to the data. indicator of the responsiveness or the activity of the tubuloglomerular feedback system. A number of situations, including salt depletion $(26,29)$, extracellular fluid volume expansion (29-31), and ureteral obstruction (32) have been identified in which the activity of the TG feedback system is modified. The results of the present experiments show that the activity of the TG feedback system is also modified by variations in protein intake: TG feedback activity is diminished when GFR is increased as a result of feeding a high protein, low carbohydrate diet for $\sim 10 \mathrm{~d}$. These results are similar to those of Schnermann and Briggs $(33,34)$, whose preliminary reports indicate that TG feedback is attenuated in otherwise normal rats fed a $50 \%$ casein diet for 4-6 wk, and in unclipped kidneys of Goldblatt hypertensive rats fed the same diet.

This decrease in TG feedback activity associated with a high protein intake is evident in the results of three experiments in which different techniques were employed. In experiment
1, suppression of SNGFR by native fluid flowing through the loop of Henle was $4.2 \mathrm{nl} / \mathrm{min}(50 \%)$ less in rats fed a high protein diet, compared with rats fed a low protein diet. This difference accounts for the bulk of the $6.3 \mathrm{nl} / \mathrm{min}$ or $21 \%$ increase in the distally measured SNGFR values of animals fed the high protein diet. Thus we believe that not only does reduction of TG feedback activity appear to contribute to the increase in filtration rate associated with a high protein intake, but it appears to contribute substantially.

Loop-microperfusion experiments, experiments 2 and 3 , demonstrate that the observed reduction in TG feedback activity in rats fed the high protein diet occurs because the TG feedback response to loop of Henle flow rates in the physiological 10-25 $\mathrm{nl} / \mathrm{min}$ range is markedly diminished. Stop-flow pressure (Fig. 3) and SNGFR (Fig. 4) started to decrease when flow into the loop of Henle exceeded $\sim 10 \mathrm{nl} /$ min in low protein animals, but in rats fed a high protein diet

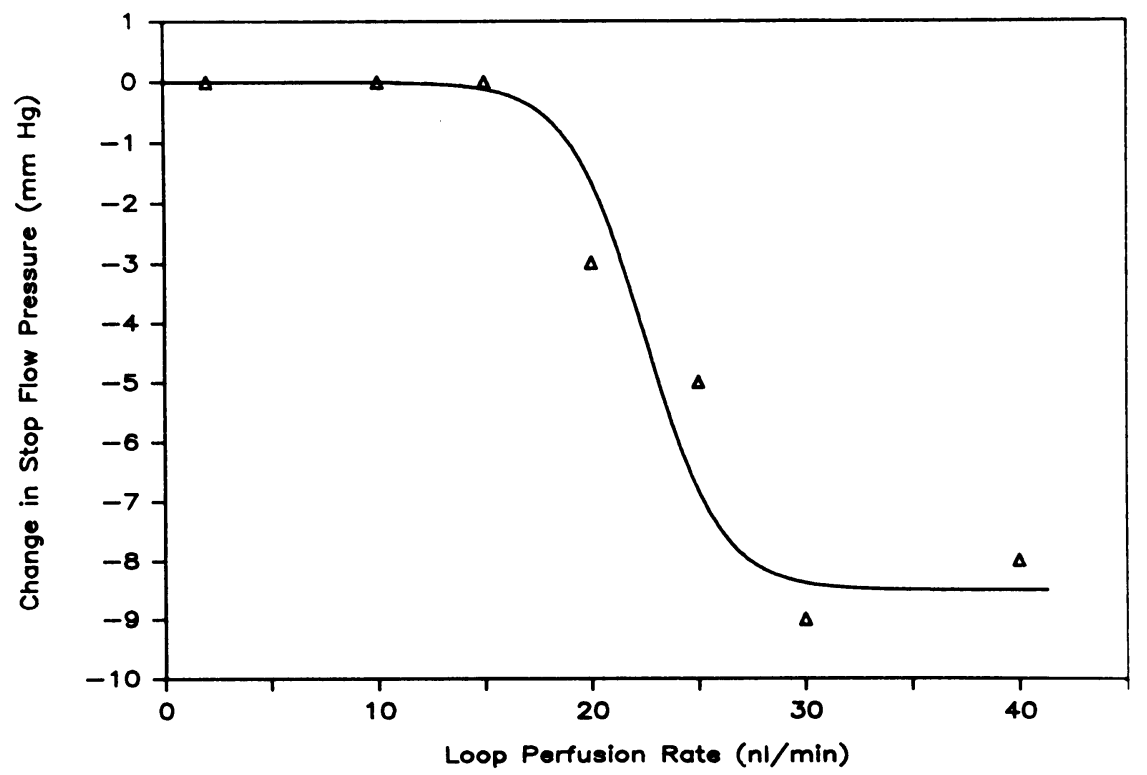

Figure 2. Example of curve fitting. Data are from one nephron in a rat fed the $40 \%$ casein diet (rat 26, experiment 2). Symbols $(\Delta)$ represent changes in stop-flow pressure $\left(P_{\mathrm{SF}}\right)$ observed at each loop-perfusion rate relative to $P_{\mathrm{SF}}$ when perfusion rate was $2 \mathrm{nl} / \mathrm{min}$. The line is the sigmoid curve (Eq. 3 in Appendix) fit to the data. 


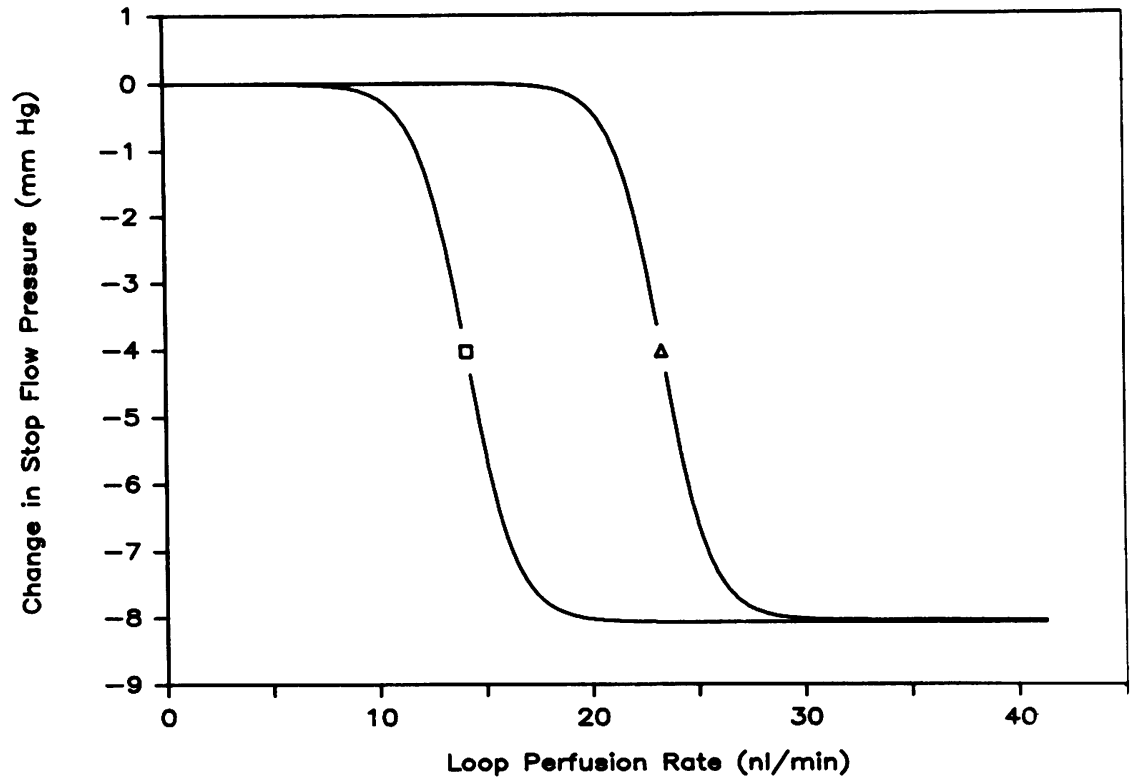

Figure 3. Comparison of all nephrons in rats fed $6 \%(\square)$ and $40 \%(\Delta)$ casein, experiment 2. The parameters of these curves were determined by averaging the parameters obtained for individual nephrons (Table IV). Measured maximum/minimum stop-flow pressure $\left(P_{\mathrm{SF}}\right)$ values were $42.2 \pm 1.0 / 34.1 \pm 1.2 \mathrm{mmHg}$ for the group fed the $6 \%$ casein diet and $45.9 \pm 1.4 /$ $37.9 \pm 1.8 \mathrm{mmHg}$ for the group fed the $40 \%$ casein group. loop flow had to be $>18 \mathrm{nl} / \mathrm{min}$ before $P_{\mathrm{SF}}$ or SNGFR began to decrease. The close correspondence between these results of experiments 2 and 3 increase our confidence in concluding that changes in dietary protein result in changes in the activity of the TG feedback system.
The results of experiments 2 and 3 are also consistent with the results of experiment 1 . In experiment 1 , the corrected late proximal flow rates were 17.8 and $18.8 \mathrm{nl} / \mathrm{min}$ in the low and high protein diet groups. The results of experiments 2 and 3 (Figs. 3 and 4) predict that, in this range of late proximal flow,

Table IV. Microperfusion, Stop-flow Pressure

\begin{tabular}{|c|c|c|c|c|c|c|c|}
\hline \multicolumn{4}{|l|}{$6 \%$} & \multicolumn{4}{|l|}{$40 \%$} \\
\hline Rat & $\mathbf{H}-\mathbf{L}$ & $\dot{V}_{1 / 2}$ & $f^{\prime}\left(\dot{V}_{1 / 2}\right)$ & Rat & $\mathbf{H}-\mathbf{L}$ & $\dot{V}_{1 / 2}$ & $\mathrm{f}^{\prime}\left(\dot{V}_{1 / 2}\right)$ \\
\hline & $m m H g$ & $\mathrm{nl} / \mathrm{min}$ & $m m H g \cdot \min / n l$ & & $m m H g$ & $\mathrm{nl} / \mathrm{min}$ & $m m H g \cdot m i n / n l$ \\
\hline \multirow[t]{5}{*}{15} & -4 & 12.2 & -1.88 & 16 & -13 & 19.7 & -3.14 \\
\hline & -8 & 14.3 & -1.87 & & -9 & 29.0 & -0.98 \\
\hline & -10 & 12.5 & -4.76 & 18 & -12 & 21.8 & -1.79 \\
\hline & -4 & 14.8 & -0.73 & & -8 & 28.6 & -0.86 \\
\hline & -6 & 20.9 & -0.84 & & -5 & 24.6 & -1.07 \\
\hline \multirow[t]{3}{*}{17} & -4 & 14.9 & -0.84 & 20 & -6 & 24.8 & -1.26 \\
\hline & -5 & 17.8 & -0.67 & & -8 & 25.3 & -1.87 \\
\hline & -7 & 15.0 & -1.56 & & -3 & 27.1 & -1.29 \\
\hline \multirow[t]{3}{*}{19} & -11 & 14.7 & -2.59 & & -9 & 24.8 & -0.78 \\
\hline & -6 & 17.4 & -0.87 & 22 & -4 & 22.3 & -1.51 \\
\hline & -12 & 16.9 & -1.95 & & -4 & 25.0 & -0.78 \\
\hline \multirow[t]{4}{*}{21} & -10 & 9.2 & -2.33 & & -3 & 27.1 & -1.11 \\
\hline & -7 & 15.0 & -1.51 & 24 & -15 & 20.3 & -3.64 \\
\hline & -11 & 14.7 & -2.61 & & -3 & 17.1 & -1.11 \\
\hline & -7 & 14.3 & -1.65 & 26 & -8 & 20.1 & -1.95 \\
\hline \multirow[t]{2}{*}{23} & -7 & 15.0 & -1.51 & & -17 & 23.0 & -2.66 \\
\hline & -20 & 12.1 & -3.21 & & -10 & 22.5 & -1.48 \\
\hline \multirow[t]{3}{*}{25} & -10 & 9.8 & -2.30 & & -8 & 22.5 & -1.21 \\
\hline & -6 & 16.5 & -0.85 & & & & \\
\hline & -4 & 14.5 & -0.97 & & & & \\
\hline Mean & 8.1 & 14.6 & -1.77 & & 8.0 & 23.6 & -1.58 \\
\hline SE & \pm 0.86 & \pm 0.60 & \pm 0.23 & & \pm 0.99 & \pm 0.76 & \pm 0.19 \\
\hline \multicolumn{4}{|c|}{$P 40 \%$ vs. $6 \%$} & & $>0.5$ & $<0.001$ & $>0.5$ \\
\hline
\end{tabular}

Individual nephron and mean values for sigmoid curve parameters, experiment $2 . \mathrm{H}-\mathrm{L}$, maximum - minimum $P_{\mathrm{SF}}$ values; $\dot{V}_{1 / 2}$, loop perfusion rate eliciting half maximal $P_{\mathrm{SF}}$ reduction; $\mathrm{f}^{\prime}\left(\dot{V}_{1 / 2}\right)$, slope of sigmoid curve at $\dot{V}_{1 / 2}$. 


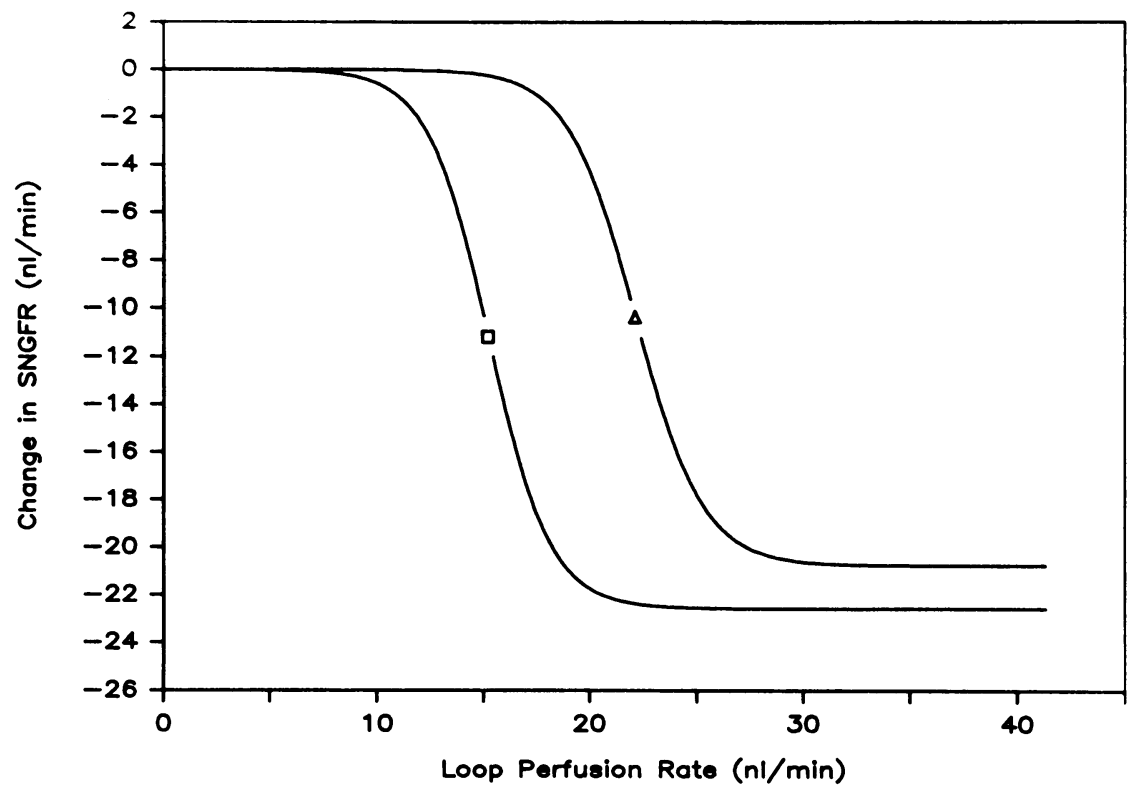

Figure 4. Comparison of all nephrons in rats fed $6 \%(\square)$ and $40 \%(\Delta)$ casein, experiment 3. The parameters of these curves represent the means of individual nephron parameters for the two diet groups (Table V). Measured maximum/minimum SNGFR values were $56.3 \pm 4.3 / 33.7 \pm 2.9 \mathrm{nl} / \mathrm{min}$ for the $6 \%$ casein group and $54.5 \pm 5.0 / 33.8 \pm 3.6 \mathrm{nl} / \mathrm{min}$ for the $40 \%$ casein group.
SNGFR would be decreased from maximal values by $\sim 20$ $30 \%$ in the low protein group, but only $3-5 \%$ in the high protein group. The differences between proximally and distally measured SNGFRs in experiment 1 (Table III) agree well with these predicted changes. In the low protein group the $\mathbf{P}-\mathbf{D}$ difference indicates a $22 \%$ reduction in SNGFR, whereas in the high protein group, the $\mathrm{P}-\mathrm{D}$ difference is only $10 \%$ of the maximum SNGFR value. We note that SNGFR measurements made at the lowest loop-perfusion rates for both diet groups in experiment 3 were $35-45 \%$ higher than proximally measured SNGFR values for both diet groups in experiment 1. These apparently high values raise two possible concerns: first, they might be the result of a measurement error; second, the late proximal flow rates in these animals might have been high enough to elicit maximal TG feedback suppression in both diet groups. We believe that neither of these concerns is necessarily valid. Although undetected measurement errors are always possible, we carefully examined each step of the measuring process and found no technical factors responsible for the higher SNGFR values. Even though the animals in exper- iments 1 and 3 were handled in the same fashion, the experiments were performed 6 mo apart. Also, as shown in Table II, kidney GFR values were $10-15 \%$ higher and urine flow values were $35-55 \%$ higher in experiment 3 compared with experiment 1 . Thus, we conclude that the higher SNGFR values in experiment 3 are real and are the result of some variation in the animals used in the two experiments.

With regard to the second concern, the high values observed for SNGFR, when loop of Henle flow rates were very low, do not necessarily mean that late proximal flow rates would have been high if tubule fluid had been permitted to flow freely through the loop of Henle. Because tubule fluid was collected in experiment 3 from early or midproximal segments we do not know the TF/ $P$ inulin ratio at the end of the proximal tubule. However, if we assume for experiment 3 that the TF/ $P$ inulin ratio was $1.7-1.9$, as it was in experiment 1 , then the late proximal flow rates can be calculated from SNGFR values. Starting with the SNGFR values $(55-56 \mathrm{nl} / \mathrm{min})$ measured at the lowest loop-perfusion rates, the late proximal flow rate would be $29-33 \mathrm{nl} / \mathrm{min}$. If tubule fluid were suddenly allowed

Table V. Microperfusion, SNGFR

\begin{tabular}{|c|c|c|c|c|c|c|c|}
\hline \multicolumn{4}{|l|}{$6 \%$} & \multicolumn{4}{|l|}{$40 \%$} \\
\hline \multirow[t]{2}{*}{ Rat } & $\mathrm{H}-\mathrm{L}$ & $\dot{V}_{1 / 2}$ & $\mathrm{f}^{\prime}\left(\dot{V}_{1 / 2}\right)$ & Rat & $\mathbf{H}-\mathbf{L}$ & $\dot{V}_{1 / 2}$ & $\mathrm{f}^{\prime}\left(\dot{V}_{1 / 2}\right)$ \\
\hline & $n l / m i n$ & $\mathrm{nl} / \mathrm{min}$ & & & $\mathrm{nl} / \mathrm{min}$ & $n l / m i n$ & \\
\hline 27 & -25.6 & 10.2 & -4.98 & 28 & -24.2 & 15.0 & -5.03 \\
\hline 29 & -19.0 & 15.3 & -1.91 & 30 & -19.7 & 21.1 & -3.69 \\
\hline 31 & -12.9 & 12.4 & -1.76 & 32 & -12.7 & 22.8 & -1.77 \\
\hline 33 & -36.0 & 18.4 & -10.10 & 34 & -33.6 & 26.5 & -2.17 \\
\hline 35 & -19.2 & 18.3 & -3.02 & 36 & -13.6 & 29.0 & -2.60 \\
\hline Mean & 22.6 & 14.9 & -4.35 & & 20.7 & 22.9 & -3.05 \\
\hline SE & \pm 3.9 & \pm 1.6 & \pm 1.55 & & \pm 3.8 & \pm 2.4 & \pm 0.59 \\
\hline \multicolumn{4}{|c|}{ P. $40 \%$ vs. $6 \%$} & & $>0.5$ & 0.025 & 0.46 \\
\hline
\end{tabular}

Individual nephron and mean values for sigmoid curve parameters, experiment 3. Headings as in Table IV. 
to flow into the loop of Henle at this rate, the feedback response curves for experiment 3 (shown in Fig. 4) show that SNGFR would be suppressed toward $34 \mathrm{nl} / \mathrm{min}$ in both diet groups. As SNGFR decreased, late proximal flow rate would fall toward $18-20 \mathrm{nl} / \mathrm{min}$. In the low protein rats a late proximal flow rate of $18-20 \mathrm{nl} / \mathrm{min}$ would be sufficient to activate fully the TG feedback system and maintain suppression of SNGFR. In the high protein rats, however, as late proximal flow fell below $30 \mathrm{nl} / \mathrm{min}$ the extent of activation of the TG feedback system would diminish and SNGFR would approach some value between 35 and $55 \mathrm{nl} / \mathrm{min}$. The higher SNGFR would maintain a higher late proximal flow rate and a new steady-state would be reached with less complete activation of TG feedback and a higher SNGFR in the high protein rats compared with more complete activation of TG feedback and a lower SNGFR in the low protein animals.

The present experiments were designed to examine the effects of $10 \mathrm{~d}$ of exposure to two extremes of dietary protein intake. Based on recommendations of the American Institute of Nutrition, laboratory rat diets contain $20-25 \%$ protein. An interesting question, not answered by the present experiments, is whether GFR and feedback activity in rats fed a "normal" protein diet would differ from both of the groups we have studied. Recent experiments in our laboratory show that rats fed 23\% protein have TG feedback responses (stop-flow pressure) that are similar to the present results in the high protein group. Interpretation of these results requires caution because the rats were obtained from a different supplier, the food was from a different manufacturer, and the rats were fed ad lib. Recognizing these limitations, it appears that a greater change in TG feedback activity occurs as the fraction of protein in the diet is increased from $6 \%$ to $23 \%$, and a smaller change occurs when protein is increased further to $40 \%$.

In addition to establishing that protein intake influences the activity of the TG feedback system, the present experiments permit inferences concerning which elements of the TG feedback system are affected by dietary protein intake. The elements of the TG feedback loop include the signal initiating responses, the sensing mechanism detecting signals, the transmission mechanism connecting the sensing site to the effector site, and the effector mechanism. If the effector mechanism, which depends on constriction of afferent arterioles, had been affected by the change in dietary protein, we would expect that the maximum response would have been altered. The similarity of the maximum response in the two groups (Figs. 3 and 4) argues against a change in the effector mechanism. If the transmission pathway between the sensing step and the effector mechanism had been affected, we would expect that the gain of the feedback response would be changed. Because the slopes of the response curves did not differ (Tables IV and V), we conclude that the gain of the transmission mechanism was not modified by the change in protein intake. The change in the function of the TG feedback system that we did observe, a shift in the position of the response curve, means that in the rats fed the high protein diet greater loop-flow rates were required to elicit the same reduction in filtration rate. We interpret this change in the positions of the threshold and $\dot{V}_{1 / 2}$ as indicating that the reduction of TG feedback activity in high protein animals is caused primarily by a change in the sensing step: either the sensing mechanism is rendered less responsive or the signal appearing at the sensing site is reduced.
Either change could explain the observation that a loop of Henle flow rate sufficient to elicit full TG suppression of GFR in rats fed a low protein diet was less effective in rats fed the high protein diet.

The exact nature of the signal is not known with certainty, but is thought to involve $\mathrm{NaCl}$ transport by macula densa cells $(13,35,36)$. The delivery of $\mathrm{NaCl}$ to the macula densa segment might have been reduced in the high protein rats if salt reabsorption by more proximal nephron segments was increased. Consistent with this possibility is the recent finding that sodium-hydrogen exchange in brush-border vesicles is increased by protein feeding (37). It is also likely that the urea concentration in fluid reaching the macula densa segment is increased by protein feeding. It does not seem possible, however, that an elevated urea concentration would tend to reduce TG feedback activity in view of the results of Briggs et al. (36) that show no effect of variations in urea concentration between 10 and $360 \mathrm{mM}$.

An unresolved question is whether a reduction in the activity of TG feedback is the proximate factor increasing filtration rate in association with increased protein intake or, whether a reduction in feedback activity acts in concert with other factors modified by changes in protein intake. It may be that an initial reduction in the function of the TG feedback system reduces the normally present suppression of GFR effected by TG feedback, thus causing filtration rate to rise. Alternatively or simultaneously, it may be that other factors modified by dietary protein intake change the determinants of filtration and cause an initial SNGFR increase that is no longer as fully moderated by negative feedback control. In either case reduction of TG feedback function would permit filtration rate to rise.

At the present time it is also unclear to what extent factors independent of TG feedback can cause GFR to rise in normal animals fed a diet rich in protein. In our first experiment, we found no statistical difference in proximally measured SNGFR at the $P<0.05$ level. Similarly, we found no significant difference in the values for proximally measured SNGFR in experiment 3 when loop perfusion was $<5 \mathrm{nl} / \mathrm{min}$. Therefore, our results do not suggest that factors independent of TG feedback contribute significantly to the increase in SNGFR observed in otherwise normal animals maintained on a high protein intake for $\sim 10$ days. In contrast, Ichikawa et al. (11) and Hostetter et al. (12) found that proximally measured SNGFR values were higher in rats fed high protein diets, compared with rats fed low protein diets. It may be that under the conditions of their experiments influences on glomerular blood vessels not mediated by the TG feedback system substantially affect GFR. Their experiments differed from our experiments in several ways. First, Ichikawa et al. (11) maintained Munich-Wistar rats on the special diets for 2-4 mo with the aim of producing "chronic malnutrition" in the low protein group. Second, the rats used by Ichikawa et al. were young animals weighing $90 \mathrm{~g}$ at the start of diet treatment. Third, Hostetter et al. (12) examined the function of kidney remnants after $>90 \%$ of renal tissue had been removed and after 14-21 d of protein restriction. Given these differences, one should not necessarily expect that our experiments that study less extreme circumstances should yield results identical to theirs. The possibility remains that the differences in proximally measured SNGFR observed by Ichikawa et al. (11) and 
by Hostetter et al. (12) indicate that factors other than TG feedback mediate effects of dietary protein on GFR under some circumstances, such as in young maturing animals, or with feeding for more than $10 \mathrm{~d}$, or with greatly reduced renal mass. Given presently available data we cannot be certain of the reason for the differences between our results and those of the previous experiments. We think, however, that the differences in the way the animals were prepared provide a likely explanation. Of course, the results of the previous experiments $(11,12)$, although pointing to non-TG feedback influences on filtration, do not rule out a contribution of TG feedback to suppression of GFR after several weeks or months of a low protein intake: SNGFR was determined only by proximal collections in those studies, and it is possible that lower SNGFR values would have been observed if distal collections had also been employed.

The animals in the high protein group gained weight more quickly and often had larger kidneys than the low protein animals. This difference in growth has been observed previously (6). It is of interest that it occurs even though caloric intake was not different. Because our high protein animals in experiments 1 and 2 had larger kidneys, we wondered whether the increased GFR and reduced TG feedback activity found in these animals could be explained solely on a structural basis. To examine this possibility, we designed experiment 3 so that the kidneys of the rats fed the low protein diet would weigh at least as much as the kidneys of the rats fed the high protein diet. We found in experiment 3, as we did in experiment 1 , that the GFR of animals fed the high protein diet was higher by $\sim 25 \%$. We also found that the configuration and position of the TG feedback response curves in experiment 3 paralleled the response curves in experiment 2 . We conclude, therefore, that a functional change related to diet rather than kidney size was the major factor responsible for the higher GFR and reduced feedback activity of high protein animals.

It is known that extracellular fluid volume expansion suppresses (29-31) and extracellular fluid volume contraction augments $(26,29)$ the activity of the TG feedback system. Therefore, we also wondered whether a decrease in extracellular volume could have accounted for the relatively greater activity of TG feedback in the groups fed the low protein diet. Ichikawa et al. (11) found no difference in the plasma volumes of rats fed $6 \%$ and $40 \%$ protein diets. They observed plasma volumes of $3.47 \mathrm{ml}$ per $100 \mathrm{~g}$ body wt with $6 \%$ protein, and $3.22 \mathrm{ml}$ per $100 \mathrm{~g}$ body wt with $40 \%$ protein. The least significant difference in plasma volumes that could have been detected in their experiments was $0.37 \mathrm{ml}$ per $100 \mathrm{~g}$ body wt, an $11 \%$ difference. We found no difference in hematocrit values or in mean arterial pressure recorded during periods of kidney study. We did, however, find that blood pressure recorded immediately after placement of the arterial catheter was higher in rats fed the low protein diet. In addition, we found that sodium excretion was twice as great in the low protein group of experiment 3. Both of these changes argue against extracellular fluid volume being less in the rats fed the low protein diet. Judging from these data, it may even be that extracellular fluid volume was higher in the groups receiving the low protein diet. A reduction in extracellular fluid does not appear to explain the greater activity of TG feedback in the low protein groups.

Because the phosphate content of the high protein diet was
$25 \%$ higher than that of the low protein diet in the present and previous $(11,12)$ experiments, our results do not completely exclude the possibility that dietary phosphate participates in the resetting of TG feedback. Harter et al. (38) found in dogs that marked hypophosphatemia (caused by a 25 -fold reduction in phosphate intake and administering aluminum carbonate) was associated with a $17 \%$ reduction in creatinine clearance. Conceivably this reduction in clearance could have been accompanied by an increase in TG feedback activity. Since our diets involved a much smaller difference in phosphate intake, we believe that it is unlikely that phosphate intake was a major factor in the present study.

Technical comments. Because no method of assessing the activity of the TG feedback system is entirely without limitations, we employed three different approaches. A frequently cited concern about techniques requiring collection of tubule fluid is that artifactual changes in SNGFR may be introduced by the collection technique through alteration of intratubular pressure (particularly during collections from the proximal tubule) (21). In experiment 1 we attempted to avoid altering pressure in Bowman's space by collecting fluid from the distal end of the proximal tubule and by not applying suction on the collection pipette. In experiment 3 , where it was necessary to collect fluid from a segment closer to the glomerulus, a pressure-recording pipette was positioned in the early proximal tubule so that we could monitor proximal tubule pressure during collections. Under these conditions we found, as we did in experiments 1 and 2, that TG feedback activity was diminished in rats fed a high protein diet.

The stop-flow pressure technique has the advantage that it permits continuous assessment of feedback activity while loopflow rate is varied over a range of flows. However, several criticisms have been directed at this technique. First, concern has been expressed that stopping glomerular filtration may increase glomerular capillary pressure, $P_{G C}(17)$. Second, although parallel TG feedback-mediated changes in stop-flow pressure $\left(P_{\mathrm{SF}}\right)$ and $P_{\mathrm{GC}}$ have been observed in the same experiments (39-42), recent reports indicate that under some circumstances SNGFR can change without changes in $P_{\mathrm{SF}}$ or $P_{\mathrm{GC}}$ (39). It is not clear that either of these criticisms render measurements of $P_{\mathrm{SF}}$ invalid as an index of changes in $P_{\mathrm{GC}}$ caused by TG feedback. Other investigators have reported that $P_{\mathrm{GC}}$ is not elevated when filtration is stopped $(40,43)$. Even if $P_{\mathrm{GC}}$ were elevated when filtration is stopped, changes in stopflow pressure can still accurately reflect changes in $P_{\mathrm{GC}}$ (39, 40). Nevertheless, because of these concerns, we performed experiment 3 to observe the filtration rate directly. The results show that changes in SNGFR caused by variations in the loopperfusion rate closely parallel the changes in $P_{\mathrm{SF}}$ observed in experiment 2 . Therefore, change in dietary protein intake does affect feedback control of GFR and it appears that stop-flow measurements are a reliable index of TG feedback activity under the conditions of the present study.

In summary, we have demonstrated that otherwise normal rats fed a diet rich in protein and low in carbohydrate have increased whole kidney GFR and proportionate increases in distally measured but not proximally measured SNGFR. These increases in filtration rate are associated with a $50 \%$ reduction in the activity of the tubuloglomerular feedback system. This decrease in the response of the TG feedback system appears to contribute substantially to the increase in GFR associated 
with high protein intake. Loop-perfusion experiments suggest that the sensing step of the feedback mechanism of rats fed a high protein diet is less fully activated by loop-flow rates that elicit full feedback suppression of GFR in rats fed a low protein diet.

\section{Appendix}

Results of the present and previous (24-26) experiments demonstrate that the relationship of SNGFR or $P_{\mathrm{SF}}$ to loop-perfusion rate approximates a sigmoid shape. As discussed by Batschelet (44), an equation for sigmoid curves can be derived from the differential equation,

$\frac{\mathrm{d} y}{\mathrm{~d} x}=a(H-y)(L-y)$.

As applied in the present study, the independent variable, $x$, is the loop-perfusion rate and the dependent variable, $y$, is the value of SNGFR or $P_{\mathrm{SF}}$. Parameters $H$ and $L$ are the maximum and minimum values of $y$. Parameter $a$ is a determinant of the slope of the sigmoid curve as discussed below. Integration, rearrangement, and application of an exponential function to Eq. 1 yields

$\frac{H-y}{y-L}=\mathrm{e}^{(\alpha-L) x+C}$,

in which parameter $C$ is a constant of integration. Solving Eq. 2 for $y$ yields an explicit solution and more useful form of the original differential equation:

$y=L+\frac{H-L}{1+\mathrm{e}^{\alpha(H-L) x+C}}=H-\frac{H-L}{1+\mathrm{e}^{-\alpha(H-L) x-C}}$.

The values for $x$ and $y$ are determined directly as experimental measurements. The values for $H$ and $L$ are determined from the data as the means of the $y$ values in the maximum and minimum plateaus. Parameters $a$ and $C$ are determined using a linear transformation of Eq. 2:

$\ln \frac{(H-y)}{(y-L)}=a(H-L) x+C$.

Least squares regression analysis (27) is applied to the transformed $y$ values to determine the slope and $y$ intercept of Eq. 4. The slope, $s$, of Eq. 4 is $a(H-L)$ and the $y$ intercept has the value, $C$.

Other useful features of the sigmoid equation follow from the above relationships. The loop-perfusion rate at which the reduction in SNGFR or $P_{\mathrm{SF}}$ is half maximal, $\dot{V}_{1 / 2}$, can be shown by substitution of $(H+L) / 2$ for $y$ in Eq. 3 to be

$\dot{V}_{1 / 2}=-\frac{C}{a(H-L)}=-\frac{C}{s}$.

Furthermore, since the slope of the sigmoid curve is described at all $x$ values by Eq. 1 (the differential form of Eq. 3), the slope of the sigmoid curve at $\dot{V}_{1 / 2}, f^{\prime}\left(\dot{V}_{1 / 2}\right)$, can be shown by substitution of $s /(H-L)$ for $a$, and $(H-L) / 2$ for $y$ in Eq. 1 to be

$\mathrm{f}^{\prime}\left(\dot{V}_{\mathrm{I} / 2}\right)=s(L-H) / 4$.

It can be shown that the value of the slope at $\dot{V}_{1 / 2}$ is the maximal slope value for all points along a given sigmoid curve.

The computations are simplified further by assigning a value of 0 to $H$ and then plotting values of SNGFR or $P_{\mathrm{SF}}$ as reductions from the baseline SNGFR or $P_{\mathrm{SF}}$ (measured when the loop-perfusion rate is $<5 \mathrm{nl} / \mathrm{min}$ ). Consequently, the normalized $y$ values in Figs. 1-4 appear as negative numbers, with increasing feedback responses corresponding to increasingly negative numbers.

\section{Acknowledgments}

We thank Dr. John Goffinet for valuable assistance with the statistical analyses and Debbie Beauvais for expert secretarial assistance.

This research was supported by the Veterans Administration, the American Heart Association, National Institutes of Health, and with funds contributed in part by the Connecticut affiliate of the American Heart Association.

\section{References}

1. Jolliffe, N., and H. W. Smith. 1931. The excretion of urine in the dog. II. The urea and creatinine clearance on cracker meal diet. Am. J. Physiol. 99:101-107.

2. Van Slyke, D. D., C. P. Rhoads, A. Hiller, and A. Alving. 1934. The relationship of the urea clearance to the renal blood flow. Am. J. Physiol. 110:387-391.

3. Pitts, R. F. 1935. The effect of protein and amino acid metabolism on the urea and xylose clearance. J. Nutr. 9:657-666.

4. Hiatt, E. P., and R. B. Hiatt. 1942. The effect of food on the glomerular filtration rate and renal blood flow in the harbor seal (Phoca vitulina 1.). J. Cell. Comp. Physiol. 19:221-227.

5. Pitts, R. F. 1944. The effects of infusing glycin and of varying the dietary protein intake on renal hemodynamics in the dog. Am. J. Physiol. 142:355-365.

6. Dicker, S. E. 1949. Effect of the protein content of the diet on the glomerular filtration rate of young and adult rats. J. Physiol. (Lond.). 108:197-202.

7. Schoolwerth, A. C., R. S. Sandler, P. M. Hoffman, and S. Klahr. 1975. Effects of nephron reduction and dietary protein content on renal ammoniagenesis in the rat. Kidney Int. 7:397-404.

8. O'Connor, W. J., and R. A. Summerill. 1976. The effect of a meal of meat on glomerular filtration rate in dogs at normal urine flows. J. Physiol. (Lond.). 256:81-91.

9. Bosch, J. P., A. Saccaggi, A. Lauer, C. Ronco, M. Belledone, and S. Glabman. 1983. Renal functional reserve in humans. Am. J. Med. 75:943-950.

10. Hostetter, T. H. 1984. Renal hemodynamic response to a meat meal in humans. Kidney Int. 25:168. (Abstr.)

11. Ichikawa, I., M. L. Purkerson, S. Klahr, J. L. Troy, M. Martinez-Maldonado, and B. M. Brenner. 1980. Mechanism of reduced glomerular filtration rate in chronic malnutrition. J. Clin. Invest. 65:982-988.

12. Hostetter, T. H., J. L. Olson, H. G. Rennke, M. A. Venkatachalam, and B. M. Brenner. 1981. Hyperfiltration in remnant nephrons: a potentially adverse response to renal ablation. Am. J. Physiol. 241(Renal Fluid Elec. Physiol. 10):F85-F93.

13. Schnermann, J., F. S. Wright, J. M. Davis, W. v. Stackelberg, and G. Grill. 1970. Regulation of superficial nephron filtration rate by tubuloglomerular feedback. Pflugers Archiv. Eur. J. Physiol. 318:147175.

14. Häberle, D. A. 1975. Influence of filtration rate on the rate of para-aminohippurate secretion by the rat kidney. Kidney Int. 7:385396.

15. Blantz, R. C., and K. S. Konnen. 1977. Relation of distal tubular delivery and reabsorptive rate to nephron filtration. Am. J. Physiol. 233:F315-F324.

16. Bell, P. D., C. Thomas, R. H. Williams, and L. G. Navar. 1978. Filtration rate and stop-flow pressure feedback responses to nephron perfusion in the dog. Am. J. Physiol. 234(Renal Fluid Elec. Physiol. 3):F154-F165.

17. Ichikawa, I. 1982. Direct analysis of the effector mechanism of the tubuloglomerular feedback system. Am. J. Physiol. 243:F447F455. 
18. Briggs, J. P., and F. S. Wright. 1979. Feedback control of glomerular filtration rate: site of the effector mechanism. Am. J. Physiol. 236:F40-F47.

19. Tucker, B. J., R. W. Steiner, L. C. Gushwa, and R. C. Blantz. 1978. Studies on the tubulo-glomerular feedback system in the rat. The mechanism of reduction in filtration rate with benzolamide. $J$. Clin. Invest. 62:993-1004.

20. Amador, E., and J. Urban. 1972. Simplified serum phosphorus analyses by continuous-flow ultraviolet spectrophotometry. Clin. Chem. 18:601-604.

21. Schnermann, J., J. M. Davis, P. Wunderlick, D. Z. Levine, and M. Horster. 1971. Technical problems in the determination of nephron filtration rate and their functional implications. Pflugers Arch. Eur. J. Physiol. 329:307-320.

22. Gertz, K. H., and J. W. Boylan. 1973. Glomerulo-tubular balance. Handb. Physiol. (Sect. 8: Renal Physiol.) 763-790.

23. Häberle, D. A., and H. von Baeyer. 1983. Characteristics of glomerulotubular balance. Am. J. Physiol. 244:F355-F366.

24. Müller-Suur, R., B-J. Norlén, and A. E. G. Persson. 1980. Resetting of tubuloglomerular feedback in rat kidneys after unilateral nephrectomy. Kidney Int. 18:48-57.

25. Briggs, J. 1982. A simple steady-state model for feedback control of glomerular filtration rate. Kidney Int. (Suppl. 12) 22:S143S150.

26. Selén, G., R. Müller-Suur, and A. E. G. Persson. 1983. Activation of the tubuloglomerular feedback mechanism in dehydrated rats. Acta Physiol. Scand. 117:83-89.

27. Snedecor, G. W., and W. G. Cochran. 1967. Statistical Methods The Iowa State University Press, Ames, IA. 3-593.

28. Wallenstein, S., C. L. Zucker, and J. L. Fleiss. 1980. Some statistical methods useful in circulation research. Clin. Res. 47:1-9.

29. Dev, B., C. Drescher, and J. Schnermann. 1974. Resetting of tubuloglomerular feedback sensitivity by dietary salt intake. Pflugers Arch. (Eur. J. Physiol.) 346:263-277.

30. Schnermann, J., M. Hermle, E. Schmidmeier, and H. Dahlheim. 1975. Impaired potency for feedback regulation of glomerular filtration rate in DOCA escaped rats. Pflugers Arch. Eur. J. Physiol. 358:325338.

31. Persson, A. E. G., J. Schnermann, and F. S. Wright. 1979. Modification of feedback influence of glomerular filtration rate by acute isotonic extracellular volume expansion. Pflugers Arch. Eur. J. Physiol. 381:99-105.

32. Persson, A. E. G., J. Wahlberg, R. Safirstein, and F. S. Wright.
1984. The effect of two hours complete unilateral obstruction on the tubuloglomerular feedback control. Acta Physiol. Scand. 122:35-43.

33. Schnermann, J., and J. P. Briggs. 1984. The effect of variations in protein intake on tubuloglomerular feedback and single nephron filtration rate in rats with normal and elevated blood pressures. Renal Physiol. 7:258-259. (Abstr.)

34. Schnermann, J., J. P. Briggs, M. Gokel, and G. Schubert. 1984. Normal glomerular structure and function in non-clipped kidneys of Goldblatt hypertensive rats fed a low protein diet. Kidney Int. 25:291. (Abstr.)

35. Schnermann, J., J. P. Briggs, and F. S. Wright. 1981. Feedbackmediated reduction of GFR during infusion of hypertonic saline. Kidney Int. 20:462-468.

36. Briggs, J. P., J. Schnermann, and F. S. Wright. 1980. Failure of tubule fluid osmolarity to affect feedback regulation of glomerular filtration. Am. J. Physiol. 239:F427-F432.

37. Harris, R. C., J. L. Seifter, and B. M. Brenner. 1984. Uninephrectomy and dietary protein excess enhance $\mathrm{Na}-\mathrm{H}$ exchange in rat renal brush border membrane vesicles (BBMV). Kidney Int. 25:302. (Abstr.)

38. Harter, H. R., A. Mercado, W. E. Rutherford, H. Rodriguez, E. Slatopolsky, and S. Klahr. 1974. Effects of phosphate depletion and parathyroid hormone on renal glucose reabsorption. Am. J. Physiol. 227:1422-1427.

39. Blantz, R. C., L. C. Gushwa, and A. E. G. Persson. 1984. Tubuloglomerular feedback (TGF) released response in glomerular capillary hydrostatic pressure $\left(P_{G}\right)$ and nephron filtration rate (SNGFR) in hydropenic (H) and in angiotensin (AII) and prostaglandin (PG) blocked rats (B). Kidney Int. 25:286. (Abstr.)

40. Briggs, J. P. 1984. The effect of loop of Henle flow on glomerular capillary pressure. Renal Physiol. 7:311-320.

41. Israelit, A. H., F. C. Rector, and D. W. Seldin. 1973. The influence of perfusate composition and perfusion rate on glomerular capillary hydrostatic pressure. Am. Soc. Nephrol. 6:53. (Abstr.)

42. Navar, L. G., M. Reddington, P. D. Bell, and D. W. Ploth. 1983. Tubuloglomerular feedback mediated reductions in directly measured glomerular capillary pressure in response to increased distal volume delivery. Physiologist. 26:A-127. (Abstr.)

43. Blantz, R. C., A. H. Israelit, F. C. Rector, Jr., and D. W. Seldin. 1972. Relation of distal tubular $\mathrm{NaCl}$ delivery and glomerular hydrostatic pressure. Kidney Int. 2:22-32.

44. Batschelet, E. 1979. Introduction to Mathematics for Life Scientists. Third edition. Springer-Verlag, Berlin. 324-327. 